MEMÓRIA

\title{
Epidemias, vacinas e tecnologia: experiência de inovação em ciência, tecnologia e saúde na Fiocruz em meados dos anos 1970
}

Nara Azevedo*

Luiz Otávio Ferreira**

Em 1975, a Fundação Oswaldo Cruz (Fiocruz) criou, em sua sede na cidade do Rio de Janeiro, um laboratório para a produção em escala industrial da vacina contra a meningite. Essa iniciativa não se relacionava à tradicional área de produção de vacinas e soros do antigo Instituto Oswaldo Cruz, que, juntamente com outras instituições do Ministério da Saúde, deu origem à Fiocruz em 1970. Tratava-se de uma novidade: a doação de uma unidade industrial completa por parte de uma empresa estrangeira. ${ }^{1}$

Esse caso singular está registrado em um conjunto de documentos manuscritos e fotográficos que compõem o acervo histórico da Fiocruz. Desse conjunto, foi selecionado para análise o "Contrato de doação de equipamentos e de prestação gratuita de assistência técnica entre a Fiocruz e a Fondation Mérieux", pois, por sua própria natureza, dá prova da existência histórica do caso, além de os termos

* Programa de Pós-Graduação em História das Ciências e da Saúde, Fundação Oswaldo Cruz (Fiocruz), Rio de Janeiro (RJ), Brasil. E-mail: nazevedo@fiocruz.br

** Departamento de Ciências Sociais e Educação, Universidade do Estado do Rio de Janeiro (UERJ), Rio de Janeiro (RJ); Programa de Pós-Graduação em História das Ciências e da Saúde, Fundação Oswaldo Cruz (Fiocruz), Rio de Janeiro (RJ), Brasil. E-mail: lotavio@fiocruz.br

1 A análise aqui proposta se baseia na discussão desenvolvida em Azevedo (2000). 
firmados ajudarem a compreender a importância desse fato na história da ciência e tecnologia em saúde, ${ }^{2}$ como pretendemos demonstrar nesse texto.

Trata-se de um contrato sucinto, que tem como objeto a doação de equipamentos para a instalação de uma unidade-piloto de produção de vacinas bacterianas. O foco inicial seria a vacina bivalente contra a meningite meningocócica dos tipos A e C. Incluíam-se como objetivo a formação técnica de pessoal, no Brasil e na França, e estudos para eventuais adaptações da técnica de produção industrial, de modo a permitir o uso de materiais e instalações já existentes. A Fundação Mérieux ${ }^{3}$ assumiria várias obrigaçôes, tais como indicação de equipamentos e materiais a serem comprados no Brasil, supervisão da instalação e da operação da unidade-piloto durante o primeiro ano por técnicos franceses enviados ao Brasil, fornecimento de planos e projetos para obras de construção e modificações nas edificações da Fiocruz, dentre outras. Em contrapartida, à Fiocruz caberia arcar com todos os serviços e custos implicados na importação, instalação e operação dessa unidade industrial, bem como investir 10 milhôes de cruzeiros para constituir um fundo para o desenvolvimento da produção de imunizantes, que contaria também com recursos provenientes da contribuição de entidades públicas e privadas, de incentivos fiscais, dotaçôes, doações e outras fontes. Um último item, sem conexão com a unidade-piloto, previa a formação de uma sociedade de economia mista para implementar uma unidade industrial de vacinas e fracionamento de sangue, cujo acionista majoritário seria a Fiocruz.

Como se pode perceber, o contrato de doação revela mais do que o seu próprio objeto. A unidade-piloto era uma plataforma para fabricação de vacinas bacterianas, e não se restringia àquela contra a meningite. Essa característica é complementar à criação do fundo de investimentos que sustentaria futuros desenvolvimentos de produtos entre as duas instituiçōes. É também coerente com esses propósitos a ideia de constituir uma empresa de economia mista para a fabricação de vacinas e fracionamento de sangue, cujo acionista majoritário seria a Fiocruz. Em suma, as cláusulas do contrato estipulavam propósitos que iam além da transferência da tecnologia que forneceria à Fiocruz o domínio do ciclo tecnológico completo da produção da vacina contra a meningite. Esse era apenas o terreno sobre o qual

2 Os documentos manuscritos citados pertencem ao Fundo Presidência, que integra o arquivo histórico sob a guarda do Departamento de Arquivo e Documentação da Casa de Oswaldo Cruz/Fiocruz.

3 A Fundação Marcel Mérieux foi criada em 1967 pelo médico Charles Mérieux (1907-2001) como uma associação sem fins lucrativos para contribuir para a pesquisa, o treinamento e a disseminação da informação no campo da biologia e da saúde animal e humana. Desde 1947 ele presidia o Instituto Mérieux, dedicado ao desenvolvimento e produção de vacinas animais e humanas, fundado por seu pai, Marcel Mérieux, em 1897. O acordo com a Fiocruz envolveu ambas as instituiçôes. 
se projetavam empreendimentos mais ousados e duradouros. Vejamos a seguir as circunstâncias que emolduraram o desenrolar desse caso.

\section{A Fiocruz e as políticas públicas de saúde, ciência e tecnologia}

O estabelecimento do laboratório para a produção de vacina contra a meningite na Fiocruz pode ser associado, à primeira vista, à reação do governo do general Ernesto Geisel (1975-1979) ao surto de epidemia de meningite do tipo C, que, desde 1971, se manifestava em São Paulo e que assumiu grandes proporçôes a partir de 1974, atingindo outros estados. Apesar de o governo tentar ocultar a dimensão do problema até então, somente naquele ano as estatísticas oficiais registraram 2.575 mortes em hospitais paulistas. No mesmo período, no Rio de Janeiro, foram notificadas 1.500 internaçôes hospitalares e cerca de 400 mortes. No segundo semestre de 1974 , houve um recrudescimento do surto, com uma média de 14 óbitos por dia e 24.458 internações hospitalares em todo o país (BENCHIMOL, 2001, p. 326).

Nessa perspectiva, o laboratório da Fiocruz poderia representar mais um caso a reproduzir o padrão utilitário que marcou a criação dos institutos públicos de pesquisa e produção de vacinas e soros ao longo do século XX. Conforme mostra a literatura sobre o tema, esses institutos foram fundados para resolver idênticos episódios epidêmicos ou então problemas relacionados à produção agrícola, mantendo-se com dificuldade e até desaparecendo assim que a solução, mesmo que provisória, fosse encontrada. ${ }^{4}$

Contudo, é possível verificar que não foi o que ocorreu no caso da vacina contra a meningite. As circunstâncias dessa vez propiciaram um resultado distinto, promotor de uma inovação institucional e técnico-científica, com efeitos duradouros para a Fiocruz e, por conseguinte, para o país no que concerne à produção de imunobiológicos. Afinal, a unidade-piloto de fabricação da vacina contra a meningite foi um dos pilares da criação, em 1976, do então denominado Laboratório de Tecnologia em Produtos Biológicos de Manguinhos, subintitulado Bio-Manguinhos (atual Instituto de Tecnologia em Imunobiológicos Bio-Manguinhos). Esse, por sua vez, desempenhou papel fundamental para desencadear concretamente o projeto governamental, então em seu início, de transformar a Fiocruz em um dos instrumentos a serviço da política de ciência e tecnologia do setor saúde, estabelecida pelo recém-formulado II Plano Básico de Desenvolvimento Científico e Tecnológico (PBDCT). Nessa perspectiva, os institutos de pesquisa ligados ao Ministério da Saúde deveriam

4 Para uma discussão sobre o padrão utilitário ver Stepan (1976) e Schwartzman (1979). 
promover a articulação entre as ações de saúde e a política de ciência e tecnologia em prol do desenvolvimento nacional. Para tanto, de acordo com o ministro Paulo de Almeida Machado, seria necessário superar a crise de produtividade em que tais instituições estavam mergulhadas.

Essa tendência deveria ser invertida de modo a permitir o desenvolvimento e a atualização de tecnologias, principalmente no campo da produção de imunobiológicos, que, graças à engenharia genética, vinha sofrendo avanços em termos das técnicas biotecnológicas. ${ }^{5}$ A eclosão da epidemia de meningite evidenciava não apenas o despreparo administrativo dos programas de imunização para organizar a campanha de vacinação no país, mas também a dependência da importação de soros e vacinas. Apesar da larga tradição brasileira nesse campo, o país continuava dependente de importaçôes tanto do pacote das chamadas vacinas universais - tríplice (DTP), poliomielite e antimeningocócica -, quanto de uma série de outros produtos indispensáveis às ações sanitárias de rotina. A epidemia tornou mais agudo um problema crônico: o descompasso entre a capacidade industrial (pública e privada) instalada no país e a demanda da saúde pública.

Nesse sentido, a Fiocruz, que desde sua criação em 1970 permanecia sem um papel definido, deveria ser percebida como estratégica para as ações de profilaxia e controle das doenças endêmicas, conforme argumenta o ministro Almeida Machado ao justificar a proposta de sua reformulação para o ministro chefe da Secretaria de Planejamento, João Paulo dos Reis Velloso. ${ }^{6}$

Ao ser designado para a presidência da Fiocruz para implementar a reforma pretendida pelo ministro, Vinicius da Fonseca, economista do Instituto de Planejamento e Economia Aplicada (Ipea) da Secretaria de Planejamento (Seplan) da Presidência da República, procurou cumprir essa expectativa, concedendo prioridade à produção de vacinas. De acordo com Fonseca, essa área requeria uma extensa modificação, desde a redefinição da pauta de produção, passando pela reformulação da infraestrutura física e administrativa, a modernização de equipamentos e a renovação de pessoal, até a implantação da atividade de desenvolvimento tecnológico (FONSECA, 1979, p. 33). Mas o grande alvo de Fonseca era a vacina contra a meningite, seja porque o ministro da Saúde decidiu, em 1974, vacinar toda a população brasileira entre janeiro e outubro do ano seguinte, seja porque por meio dela se deparou com circunstâncias favoráveis à realização de planos mais ambiciosos para a Fiocruz e para o país.

5 Conferência. Paulo de Almeida Machado, 1975. FOC/ COC/DAD/AI-FP, Cx.11, m.11.

6 Separ no 02/SM-Bab. de 7/01/1975. Carta de Paulo de Almeida Machado ao ministro chefe da Secretaria de Planejamento da Presidência da República. FOC/COC/DAD/AI-FP, Cx. 10, m. 2. 


\section{Unidade-piloto de vacina contra a meningite: a cooperação Fiocruz - Mérieux}

A oportunidade apareceu quando o ministro Velloso designou Vinicius da Fonseca para adquirir a vacina contra a meningite junto a produtores internacionais. Naquele momento só o Instituto Mérieux na França fabricava a vacina bivalente (meningocócico tipos A e C). Em viagem à Europa, em 1974, Fonseca negociou a compra de cerca de 80 milhôes de doses de vacina, que chegaram ao Brasil em março do ano seguinte. Ao mesmo tempo, aproveitando-se da posição de comprador de tamanho volume de vacinas, ele propôs um acordo de cooperação a Charles Mérieux, visando à transferência da tecnologia da vacina contra a meningite, acompanhada da doação da unidade industrial completa.

Para Fonseca, a internalização dessa tecnologia funcionaria como uma plataforma para a fabricação posterior de outros imunobiológicos, o que, no futuro, asseguraria a autossuficiência tecnológica capaz de inverter a tendência da integral e crônica dependência de importaçôes para suprir as necessidades dos programas de controle de doenças e de imunização da população. Nessa perspectiva, deveria se considerar a possibilidade de constituição de joint ventures tecnológicas, reunindo capital nacional, privado e até mesmo público, e estrangeiro (FONSECA, 1977). Além disso, o presidente da Fiocruz tinha a convicção de que a realização de um processo autóctone de demanda tecnológica representava um estímulo ao desenvolvimento científico local. A compra de pacotes tecnológicos significava a marginalização da ciência nacional, que tendia dessa maneira a "refugiar-se em torres-de-marfim, desorientada e alienada" da sociedade. ${ }^{7}$

A proposta de cooperação entre a Fiocruz e o Instituto Mérieux, embora contasse com o apoio inicial de Charles Mérieux, não foi aceita sem resistência por parte de seu filho, Alain Mérieux, que presidia o Instituto Mérieux e fez inúmeras exigências no sentido de controlar a unidade-piloto. Seu sócio, o grupo químico farmacêutico Rhône-Poulenc, requeria como contrapartida a fabricação de outras vacinas humanas, em particular sarampo e poliomielite, o que lhes abriria o mercado brasileiro e latino-americano, dominado então pelas empresas farmacêuticas norte-americanas (FONSECA, 1995, fita 10)

Apesar da difícil negociação, segundo Fonseca, em 9 de outubro de 1975 foi celebrado o acordo de cooperação técnica para a doação da unidade-piloto, composta

\footnotetext{
7 Discurso de Vinicius da Fonseca proferido em 15/09/1978. FOC/COC/DAD/AI-FP, Cx.14,m.1.
} 
por 319 itens de diferentes espécies de componentes de laboratório, cujo valor foi avaliado em cerca de 2 milhões de cruzeiros. Para sua instalação foi escolhido o Pavilhão Rockefeller, antiga edificação do Instituto Oswaldo Cruz onde se fabricava a vacina contra a febre amarela, que sofreu diversas alterações para se adequar às exigências técnicas da fabricação da vacina. ${ }^{8}$

Inicialmente seria utilizado um fermentador de 100 litros, prevendo-se a produção de 300 mil doses mensais, que poderia ser expandida de acordo com as necessidades do Ministério da Saúde. ${ }^{9}$ Tratava-se do primeiro laboratório no país a utilizar em escala a técnica de fermentação controlada para a produção de vacinas bacterianas, com extração e purificação de polissacarídeos, e a ultracentrifugação. A versatilidade da técnica permitia aplicá-la à produção de outras vacinas bacterianas, tais como difteria, coqueluche, cólera, tifo. ${ }^{10}$

Em maio do ano seguinte, após as adaptações da infraestrutura do Pavilhão Rockefeller, o laboratório começou a ser montado pelos engenheiros franceses. Um pouco antes, em abril, começou a formação da equipe. O núcleo inicial fora contratado por Fonseca no final do ano anterior, sendo composto por dois engenheiros químicos, Eduardo Leser e Pablo Angel Podlech, ${ }^{11}$ e por Wantuil Corrêa Cunha, que pertencia à área de produção do IOC. Naquele momento eles estavam retornando do treinamento de quatro meses nas dependências do Instituto Mérieux em Lyon e iniciaram a seleção de candidatos para os diversos setores, por meio de um anúncio no jornal. Rememorando o processo, o coordenador inicial do laboratório, Leser, relata que naquele momento foram contratados 21 técnicos e quatro funcionários administrativos, a maioria jovem, vários estudantes de biologia e de química, e sem experiência profissional no campo da produção de vacinas:

A única pessoa que nos procurou e tinha mexido um pouco com vacinas era o Silvio Valle Moreira, veterinário que tinha feito estágio no Instituto Vital Brasil. Era o único, ninguém mais! Na verdade ficamos treinando a equipe durante um tempo muito longo. O Wantuil que tinha experiência em bacteriologia médica teve

8 Em carta a Charles Merieux, datada de 13 de outubro de 1975, Fonseca apresentou o plano para a instalação do laboratório na edificação, detalhando a distribuição espacial dos equipamentos, bem como as inúmeras modificaçôes que seriam feitas desde a pintura, passando pelas redes de água potável, eletricidade, ar comprimido e vapor, até o tratamento antisséptico de rejeitos, entre outras especificaçōes técnicas exigidas para instalar os equipamentos. FOC/COC/DAD/AI-FP, Cx.10, m. 3 (B).

9 Noticiário no I/76. Gabinete da Presidência. FOC/COC/DAD/AI-FP, Cx. 19, m.2.

$10 \mathrm{Na}$ época, era pouco generalizada a cultura bacteriana em fermentadores de grande capacidade (de 500 a 1.000 litros) para a obtenção da massa microbiana utilizada na fabricação da vacina (HOMMA, 1998).

11 Ambos foram indicados ao presidente da Fiocruz por Walter Borzani, engenheiro químico, professor da USP e, na época, presidente da Fapesp. 
uma importância muito grande no treinamento do grupo contratado. Fazíamos um rodízio pelos vários setores para treinar todos em tudo (LESER, 1996, fita 2).

Logo em seguida, em 14 de junho de 1976, com a presença de Charles Mérieux, do presidente da República, Ernesto Geisel, e de outras autoridades, foi inaugurada a unidade-piloto de produção de vacinas bacterianas. Embora várias atividades tenham sido iniciadas, a operação plena ocorreu um ano depois, em virtude de vários problemas técnicos, quando 300 mil doses foram produzidas, sendo 5 mil doadas aos governos da Nigéria e do Paraguai. Em 1978, a unidade-piloto já havia produzido cerca de 10 milhōes de doses desde o início das atividades. ${ }^{12}$

\section{Comentários finais}

A experiência da unidade-piloto ocorreu há mais de 40 anos e vale ser lembrada não apenas por ter sido bem-sucedida ao cumprir os objetivos imediatos para os quais fora implementada, mas por evidenciar a iniciativa de organização de uma capacidade endógena para a inovação de produtos e processos com efeitos duradouros.

Nessa perspectiva, esse caso contribui para a reflexão sobre as experiências de inovação institucional e técnico-científica em saúde, em particular em países menos desenvolvidos em que se verifica pequena capacitação tecnológica de base empresarial e de agentes públicos para gerar, absorver e difundir inovações. Essa insuficiente capacitação científica e tecnológica ameaça a sobrevivência em longo prazo das iniciativas de produção implantadas no país e impede os esforços voltados para a absorção de resultados mais substantivos da fronteira mundial da pesquisa e desenvolvimento (GADELHA; AZEVEDO, 2003, p. 699). A unidade-piloto, nesse sentido, evidencia como um quadro de dependência estrutural pode ser enfrentado ou atenuado em certas circunstâncias pela decisão política e a ação estratégica por parte de atores que, situados em posições-chave, atuam para gerar as condições institucionais necessárias à absorção de inovações técnico-cientificas.

A intensa movimentação de Vinicius da Fonseca é um exemplo desse tipo de protagonismo que se expressou concretamente na mobilização empenhada durante sua gestão (1975-1979) para promover a inovação institucional e técnico-cientifica. Embora não tenha sido bem-sucedido em todas as iniciativas em que se dedicou, inclusive em relação aos projetos de cooperação de longo prazo que vislumbrava com Mérieux, tal como esboçado no contrato de doação da unidade-piloto, ele con- 
tribuiu para a mudança na maneira de lidar com o problema da disponibilidade de vacinas para atender à política de saúde, até então dependente de importações. ${ }^{13}$ Ao defender a constituição de uma capacitação nacional em termos produtivos e tecnológicos mediante a estratégia de transferência de tecnologia, Fonseca forneceu um novo modelo de ação para lidar com antigos problemas.

$\mathrm{O}$ aprendizado institucional vivido naquele período, em particular a unidade-piloto, orientou o desenvolvimento posterior de Bio-Manguinhos, que, poucos anos mais tarde, colocou em prática essas ideias, se lançando a uma experiência similar à da unidade-piloto. Dessa vez tratou-se de acordos de transferência de tecnologia com o Laboratório Biken (Universidade de Osaka) ${ }^{14}$ e Japan Institute of Polyomielites Research, para produzir, respectivamente, as vacinas contra o sarampo (a partir de 1983) e contra a poliomielite (a partir de 1984). Um outro exemplo nos mesmo termos foi o acordo de cooperação com a empresa GlaxoSmithKline (GSK) envolvendo mais uma vez a meningite. Tratava-se, dessa vez, da bactéria Haemophilus influenzae tipo b (Hib), que também causa pneumonia e outras infecções graves em crianças pequenas. A transferência de tecnologia ocorreu em etapas, iniciada em 1999 e concluída em maio de 2005, quando Bio-Manguinhos adquiriu a capacitação tecnológica do ciclo completo de produção. ${ }^{15}$

Por essas e outras experiências de esforço endógeno de capacitação tecnológica, além de iniciativas relacionadas à modernização da infraestrutura e à melhoria da qualidade e aumento da capacidade produtiva, Bio-Manguinhos contribuiria de maneira decisiva para os programas de imunização do Ministério da Saúde, que, no início dos anos 1980, procurava se integrar aos crescentes esforços internacionais de imunização da população infantil, liderados pela Organização Mundial da Saúde, o Fundo das Nações Unidas para Criança (Unicef) e a Organização Pan-americana da Saúde (Opas). A partir de 1985, a instituição passou a integrar a rede de laboratórios oficiais coordenada pelo Programa de Autossuficiência Nacional em Imunobiológicos (Pasni), a partir do qual se estruturou a maior capacidade de produção de vacinas da América Latina, representando, certamente, uma das maiores no âmbito dos países menos desenvolvidos (GADELHA; TEMPORÃO, 1999).

13 Dentre outras iniciativas, Fonseca iniciou, em 1977, negociações com o Instituto Pasteur e Instituto Pasteur Produção com o intuito de estabelecer um acordo de pesquisa e de desenvolvimento de vacinas. No ano seguinte, tentou aproximação com o governo japonês para propor uma cooperação técnica para a produção de vacinas contra o sarampo e a poliomielite. Essas negociaçôes e as que ele entabulava com Mérieux foram interrompidas ao deixar a presidência da Fiocruz em março de 1979, quando o general João Batista Figueiredo assumiu a presidência da República.

14 Em 2000, foi firmado outro acordo com esse Instituto para a transferência de tecnologia da vacina contra a rubéola.

15 Sobre esse processo de transferência, ver Gadelha e Azevedo (2003). Outro acordo com essa empresa foi realizado em 2003 para a transferência de tecnologia da vacina tríplice viral (sarampo, caxumba, rubéola). 


\section{Referências bibliográficas}

AZEVEDO, N. Ciência e tecnologia em saúde no Brasil: a biotecnologia na Fundação Oswaldo Cruz. Tese (Doutorado em Sociologia) - Instituto Universitário de Pesquisas do Rio de Janeiro/Universidade Candido Mendes, Rio de Janeiro, 2000.

BENCHIMOL, J. (Coord.). Febre amarela: a doença e a vacina, uma história inacabada. Rio de Janeiro: Editora Fiocruz, 2001.

FONSECA, V. Depoimento. Projeto Memória de Manguinhos. Programa de História Oral-Casa de Oswaldo Cruz/Fiocruz. Rio de Janeiro, 1995.

. Recuperação (1975-1978). Rio de Janeiro: Artes Gráficas Fiocruz, 1979.

- Ciência em bases nacionais. Palestra proferida na Comissão de Ciência e Tecnologia da Câmara dos Deputados. Rio de Janeiro: Artes Gráficas, Fiocruz, 1977

GADELHA, C.; AZEVEDO, N. Inovação em vacinas no Brasil: experiência recente e constrangimentos estruturais. História, Ciências, Saúde. Manguinhos, v. 10, suplemento 2, p. $697-724,2003$.

GADELHA, C.; TEMPORÃO, J. A induistria de vacinas no Brasil: desafios e perspectivas. BNDES, 1999

HOMMA, A. Depoimento. Projeto O Cientista Biotecnologia em Saúde na Fiocruz. Programa de História Oral-Casa de Oswaldo Cruz/Fiocruz. Rio de janeiro, 1998.

LESER, E. Depoimento. Projeto O Cientista Biotecnologia em Saúde na Fiocruz. Programa de História Oral-Casa de Oswaldo Cruz/Fiocruz. Rio de janeiro, 1996.

SCHWARTZMAN, S. Formação da comunidade científica no Brasil. São Paulo: Editora Nacional; Rio de Janeiro: Financiadora de Estudos e Projetos, 1979.

STEPAN, N. Gênese e evolução da ciência brasileira. Rio de Janeiro: Editora Artenova, 1976. 
Contrato de doação de equipamentos e de prestação gratuita de assistên cia técnica entre a Fundação Osvaldō Cruz e a "Fondation Mérieux"

A FUNDAÇAO OSVALDO CRUZ, pessoa juríaica de direito provado, vinculada ao Ministério da Saúde, com sede à Aveni da Brasil, na cidade do Rio de Janeiro, Estado do Rio de Janeiro (doravante dencminada DONATÁAIA), neste ato representada pelo seu Presidente, $S \mathrm{r}$. VINICIUS FCNSECA, e a "FONDATION MÉRIEUX" , com sede no Boulevard des Belges no 17, na cidade de Lyon, França (doravante denominada DOADORA), neste ato representacia pelo seu Presidente, Dr. CHARIES MERIEUX, contratam entre si, por este instrumerto e na melhor forma de direito, a doação de equipamentos e a prestação gratuita de assistência técnica, subordinadas às cláusu las e condições abaixo discriminadas:

\section{CLÁUSULA PRIMEIRA - OBJETO}

1.1. O objeto deste contrato é a doação dos bens relacionados no Anexo "A", o qual faz parte integrante deste instrumento, que ora faz a DOADORA á DONATÁARIA e assim the transmite, des de já, pelo constituto possessório, o comínio, posse, direito e ação sobre os declarádos bens, de forma a poder a DONATÁ RIA deles usar, gozar e dispor nos termos deste contrato como seus que ficam sendo desta data em diante.

1.2. Os bens ora doados destinam-se à instalação de uma unidade piloto para a produção de vacinas antimeningocócicas bivalen tes, bem como de outras vacinas bacterianas, a critério da DONATÁRIA.

1.3. Além do objeto ruencionado no ítem 1.2. desta Cláusula, o pre sente contrato visa à consecução simultânea dos seguintes cbje tivos:

1.3.1. Assegurar á formação técnica de pessoal habilitado para a fabricação em escala inciustrial, e c controle ' da produção de vacinas, nas instalações da DONAT Á RIA..

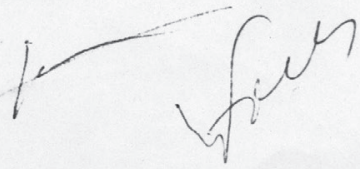


1.3.2. Promover os estudos necessários a eventuais modifi caçõ̃es e/ou adaptações nas técnicas de fabricação in dustrial de vacinas para uso humano, a fim de utiliza materiais e instalações já disponíveis no Brasil.

1.3.3. Determinar, em função dos estudos referidos no subítem 1.3.2. desta Cláusula, e de outros que venham a ser realizados, as condiçōes para a produção indus trial de imunizantes e outros produtos biológicos com utilização de tecnologia atualizada, bem como os mei os adequados à concretização deste objetivo.

\section{CLÁUSULA SEGUNDA - PROCESSAMENTO OPERACIONAL}

A preparação da vacina antimeningocócica prevista na Cláusula la. será desdobrada nas etapas essenciais a que se refere - Anexo B, o qual faz parte integrante deste contrato.

\section{CLÁUSULA TERCEIRA - OBRIGAÇOES DA DOADORA}

3.1. A DOADORA compromete-se a prestar, gratuitamente, à DO NATÁRIA, os seguintes serviços:

3.1.1. Assistência na especificaç̃o do equipamento e mate rial a ser adquirido no Brasil, com vistas ao disposto no ítem 1.2.

3.1.2. Supervisão técnica para mantagem e instalação no Bra sil, da unidade-piloto de prádução (item 1.2), responsabilizando-se pelo funcionamento eficiente de todo o equipamento.

3.1.3. Fornecimento dos planos e prrojetos das obras de cons trução e de adaptação que se fizerem necessárias nos edifícios e dependências da DONATARIA para a insta lação e montagem da unidade-piloto de produção, cạ bendo-lhe para inspecionar ais obras realizadas e 0 material instalado, para vezifficar se foram obedeci dos os planos e projetos formecidos de acordo com o disposto neste item.

3.1.4. Envio ao Brasil de pessoal técnico suficiente para o cumprimento das obrigações especificadas nesta Cláu sula, e para a orientação dos técnicos e do pessoal brasileiro, durante o tempo que for necessário. O pes

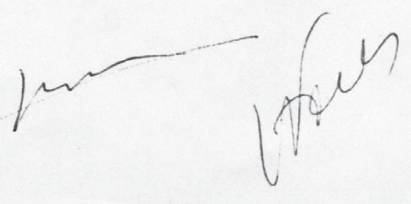


soał a que se refere este item constará de relação for necida previamente pela DOADORA, com as qualifica ções e atribuições de cada técnico, a ser aprovada pé la DONATÁRLA.

3.2. A DOADORA toma rá ainda a seu cargo, sem despesa para a DONATÁRIA salvo as especificadas no item 4.2. da Cláusula Quarta deste contrato, o estágio, na França, de técnicosbra sileiros durante o tempo necessário à assimilação das técni cas de produção de vacina. A relação dos técnicos brasilē ros, com as qualificações e atribuições de cada um deles, será fornecida previamente pela DONATÁRIA, para aprova ção pela DOADORA.

\section{CLÁUSULA QUARTA - ENCARGOS DA DONATÁRIA}

4.1. A DONATÁRIA responsabilizar-se-á pelos seguintes servi ços, atividades e providências:

4.1.1. Aprovação e registro deste contrato nas repetições competentes do governo brasileiro, bem como obten ção das licenças e demais requisitos que sejam exig $i$ dos para a transferência, para o Brasil, dos bens doa dos.

4.1.2.Transporte, desembaraço e armazenagem dos bens doados, a partir do porto de origem no exterior, até a sua instalação nas dependências da DONATÁRIA.

4.1.3.Destinação de edifícios e dependências que permitam a instalação e operação da unidade-piloto objeto desta doação, procedendo, por sua conta exclusiva, sob a supervisão técnica da DOADORA, às obras de constru ção e adaptação necessárias.

4.1.4.Adequado e eficiente suprimento de água, energia elé trica e demais serviços de infraestrutura necessários à operação da unidade-piloto objeto d̈esta doação, e esterilização dos esgotos e demais medidas de sanea mento e assepsia das instalações cabíveis, nos termos das normas internacionais que regulam a espécie.

4.1.5. Contratação, por sua conta exclusiva, do pessoal téc nico e administrativo necessário à operação da unidade-piloto objeto deste contrato, inclusive de empresas ou profissionais para execução das obras de constru

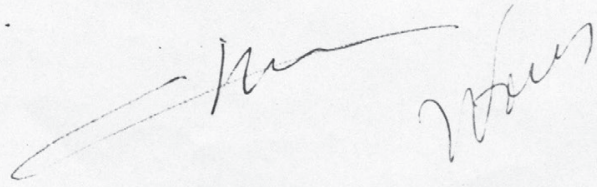




$$
\text { ção, adaptação, montagem e instalação. }
$$

4.2. A DONATÁRIA custeará todas as despesas de viagem e estada, na França, dos técnicos brasileiros que estagiarão nas depen dências da DOADORA, responsabilizando-se, quando for o cá so pelo pagamento do salário desses técnicos durante o período do estágio.

4.3. A DONATÁRIA arcará com todas as demais despesas de inves timentos e de custeio necessárias à instalação e à operação da unidade-piloto objeto deste contrato.

4.4. A DONATÁRIA destinará a importância de Cr\$10.000.000,00 (dez milhões de cruzeiros) para a constituição de um FUNDO PARA O DESENVOLVIMENTO DA PRODUÇAO DE IMUNIZAN TES, cujos recursos poderão também ser empregados na pes quisa aplicada à imunologia.

4.4.1. Além da importância referida no item 4.4. desta Cláu sula, constituirão recursos do FUNDO :

4.4.1.1. Contribuição de outras entidades, públicas ou privadas, interessadas nas iniciativas por ele financiadas.

4.4.1.2. Recursos provenientes de incentivos fiscais.

4.4.1.3. Dotações, doações e recursos de outras fontes.

4.5. As despesas decorrentes das obras, serviços e atividades pre vistos nesta Cláusula como responsánilidade da DONATÁRIA ' serão custeadas com a sua contribuição a o FUNDO.

4.6. A DONATÁRIA será a gestora do FUNDO, obedecendo a diretri zeste normas expedidas por um Conselho Consultivo de que participarão a DOADORA e a DONATARIA, bem como as eiți dades mencionadas no sub-item 4.4.1.1. desta Ciáusula.

\section{CLÁUSULA QUINTA - CRIACAOO DE SOCIEDADE DE ECONOMIA MISTA}

5.1. Imediatamente após a assinatura destie contrato, e enquanto se instala a unidade-piloto que constituz. o seu objeto, a DONAT Á RIA promoverá, com a colaboração cla DOADORA, a elaborá ção de estudo de viabilidade e projeto executivo de um conjunto industrial definitivo para a fabricação de vacinas e o fraciona. mento de sargue.
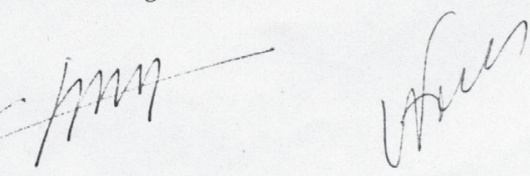
5.2. Paralelamente à elaboração do exame de viabilidade do em preendimento a que se refere o item 6.1. desta Cláusula, a DONATÁRIA providenciará, junto aos órgãos competentes do Governo Federal estudos para a criação de uma sociedade de economia mista, de cujo capital participará, majoritariamente, a DONATÁRIA e, minoritariamente, a DOADORA, a qual se encarregará de instalar e operar o referido conjunto industrial.

\section{CLÁUSULA SEXTA - ACEITACAO E DISPOSICCOES GERAIS}

6.1. A DONATÁRIA aceita a doação que ora lhe é feita, nos termos deste instrumento, cujas Cláusulas, termos e condições se compromete a cumprir, por si e por seus sucessores.

6.2. DOADORA e DONATÁRIA definirão, de forma precisa, as nor mas para a concretização plena da presente doação e os escla recimentos que se fizerem necessários, mediante aditamentos firmados por ambas as partes e que passarão a fazer parteinte grante deste instrumento.

E por estarem, assim, justas e contratadas, DOADO RA e DONATÁRIA assinam o presente instrumento, na presença das testemunhas abaixo, em 6 (seis) vias de igual teor e forma, sendo 3 (tres) em português e 3 (tres) em francês, prevalecendo a versão portuguesa em caso de dúvida.

Rio de Janeiro, 09 de $10^{\circ}$ de $1975^{-}$
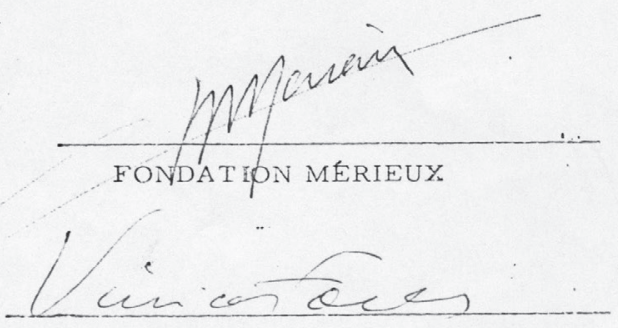

FUNDAÇAO INSTITUTO OSVALDO CRUZ

Testemunhas:

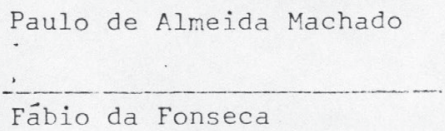

